\title{
Review Article \\ Role of Vitamin D Deficiency in Extraskeletal Complications: Predictor of Health Outcome or Marker of Health Status?
}

\author{
Idris Guessous ${ }^{1,2,3}$ \\ ${ }^{1}$ Unit of Population Epidemiology, Department of Community Medicine and Primary Care and Emergency Medicine, \\ Geneva University Hospitals, 1214 Geneva, Switzerland \\ ${ }^{2}$ Institute of Social and Preventive Medicine (IUMSP), Lausanne University Hospital, 1010 Lausanne, Switzerland \\ ${ }^{3}$ Department of Epidemiology, Rollins School of Public Health, Emory University, Atlanta, GA 1518, USA
}

Correspondence should be addressed to Idris Guessous; idris.guessous@hcuge.ch

Received 30 October 2014; Accepted 9 January 2015

Academic Editor: Domenico Santoro

Copyright (C) 2015 Idris Guessous. This is an open access article distributed under the Creative Commons Attribution License, which permits unrestricted use, distribution, and reproduction in any medium, provided the original work is properly cited.

\begin{abstract}
The relationship of vitamin D with extraskeletal complications, such as cardiovascular disease, cancer, and autoimmune disease, is of major interest considering its roles in key biological processes and the worldwide high prevalence of vitamin D deficiency. However, the causal relationships between vitamin D and most extraskeletal complications are weak. Currently, a heated debate over vitamin $\mathrm{D}$ is being conducted according to two hypotheses. In this review, we first present the different arguments that suggest a major role of vitamin D in a very broad type of extraskeletal complications (hypothesis \#1). We then present results from recent meta-analyses of randomized controlled trials indicating a lack of association of vitamin D with major extraskeletal complications (hypothesis \#2). We discuss different issues (e.g., causality, confounding, reverse causation, misclassification, and Mendelian randomization) that contribute to the favoring of one hypothesis over the other. While ultimately only one hypothesis is correct, we anticipate that the results from the ongoing randomized controlled trials will be unlikely to reconcile the divided experts.
\end{abstract}

\section{Introduction}

In humans, most circulating vitamin $\mathrm{D}$ is synthesized from cholesterol following exposure to ultraviolet B (UVB) in sunlight, whereas a smaller amount is derived from diet and dietary supplements. Diet contributes only between $10 \%$ and $20 \%$ to $25(\mathrm{OH}) \mathrm{D}$ levels but becomes more important when sunshine exposure is low [1]. Fish is the major dietary source of vitamin $\mathrm{D}$ in humans.

A summary of the synthesis and metabolism of vitamin $\mathrm{D}$, which have been described in detail in multiple reviews and textbooks [1-6], is presented below. Calcitriol, or 1,25-dihydroxyvitamin $\mathrm{D}[1,25(\mathrm{OH}) 2 \mathrm{D}]$, is the hormonally active form of vitamin $\mathrm{D}$ that is derived from the following three sources: sunlight, diet, and dietary supplements (Figure 1).

There are two precursors to active vitamin $\mathrm{D}$ hormones, vitamins $\mathrm{D}_{3}$ (cholecalciferol) and $\mathrm{D}_{2}$ (ergocalciferol). Vita$\min \mathrm{D}_{3}$ is synthesized in the skin after exposure to UVB light. Solar UVB radiation (wavelength of 290 to $315 \mathrm{~nm}$ ) penetrates the skin and converts 7-dehydrocholesterol to previtamin $\mathrm{D}_{3}$ by photolysis, which is rapidly converted to vitamin $\mathrm{D}_{3}$ [4]. Vitamin $D_{3}$ may also be obtained from some dietary sources and dietary supplements. Vitamin $\mathrm{D}_{2}$ (ergocalciferol) is derived solely from the diet (and not from UVB). Both vitamin $\mathrm{D}_{3}$ and $\mathrm{D}_{2}$ enter the blood circulation and are attracted to the vitamin $\mathrm{D}$ binding protein (VDBP).

Vitamin D in the circulation is transported to the liver, which is where it is converted by vitamin D-25-hydroxylase to 25-hydroxyvitamin $\mathrm{D}[25(\mathrm{OH}) \mathrm{D}]$. This first hydroxylation is catalyzed by the CYP27A1 enzyme. This form of vitamin $\mathrm{D}$ is thought to be biologically inactive and must be converted in the kidneys by $25(\mathrm{OH}) \mathrm{D} 1 \alpha$-hydroxylase to its biologically active form, 1,25(OH)2D [2]. This second hydroxylation is catalyzed by CYP27B1, which is located in the inner mitochondrial membrane of the proximal tubule cells of the kidneys. The 24-hydroxylation of both $25(\mathrm{OH}) \mathrm{D}$ and $1,25(\mathrm{OH}) \mathrm{D}$ to form $24,25(\mathrm{OH}) \mathrm{D}$ and $1,24,25(\mathrm{OH}) \mathrm{D}$ is the primary mechanism and the first step towards the inactivation of vitamin D metabolites. 


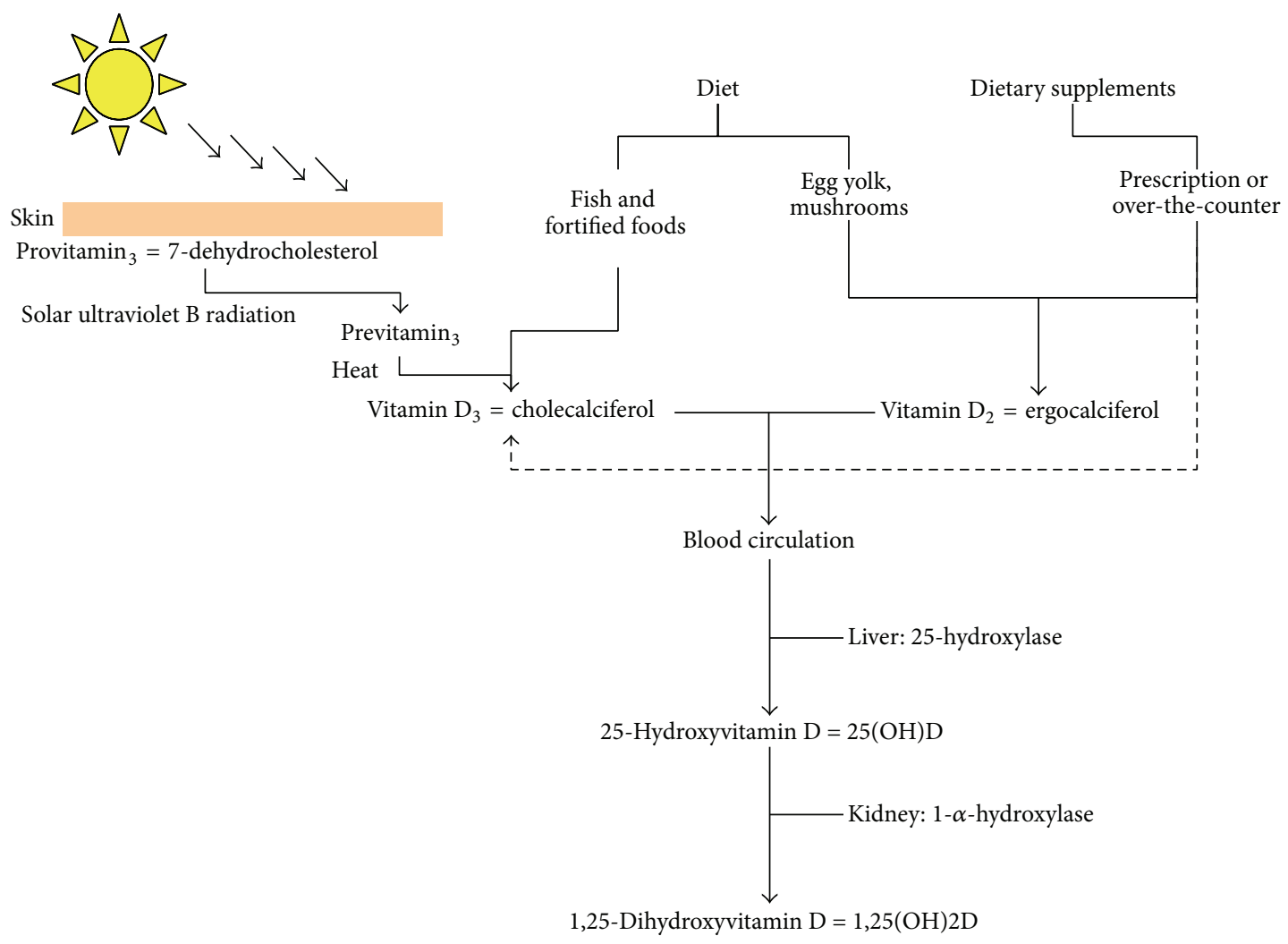

FIgURE 1: Sources of vitamin D and the first steps of vitamin D synthesis.

Genomic and Nongenomic Vitamin D Functions. The actions of vitamin $\mathrm{D}$ are largely mediated by genomic functions. Vitamin D interacts with nuclear vitamin D receptor (VDR). VDR is a ligand-induced nuclear receptor that regulates the expression of over 900 genes throughout the genome $[7,8]$. It influences the transcription of genes that are responsive to the VDR-vitamin D complex. 1,25(OH)2D dissociates from serum VDBP and enters the cell. Inside the cell, it binds to and activates VDR, and the VDR-vitamin D complex translocates from the cytosol to the nucleus, where it is joined by the retinoid $\mathrm{X}$ receptor (RXR) partner [6]. The 1,25(OH)2D-VDR-RXR complex binds to specific sequences in the promoter regions of target genes that are called vitamin $D$ response elements (VDREs), leading to the promotion and modulation of the expression of the targeted genes. $25(\mathrm{OH}) \mathrm{D}$ is less active than $1,25(\mathrm{OH}) \mathrm{D} 2$ because of its lower affinity for VDR.

Vitamin D has also some nongenomic rapid-response functions. In terms of its nongenomic functions, it functions as a steroid hormone by activating signal transduction pathways linked to vitamin D receptors on cell membranes.

\section{Hypothesis \#1: Vitamin D Is Causally Associated with Extraskeletal Complications}

\subsection{Vitamin D Deficiency and Associated Seasonal and Geographic Patterns}

2.1.1. High Prevalence of Vitamin D Deficiency. The worldwide high prevalence of vitamin $\mathrm{D}$ deficiency is often presented as being clearly linked with the high burden of extraskeletal complications. In Europe, the mean serum 25(OH)D levels (conversion factor for 25(OH)D: $1 \mathrm{ng} / \mathrm{mL}=2.496 \mathrm{nmol} / \mathrm{L}$ ) reported in population-based studies have varied from $18 \mathrm{ng} / \mathrm{mL}(29 \mathrm{nmol} / \mathrm{L})$ in Italy to $30 \mathrm{ng} / \mathrm{mL}(75 \mathrm{nmol} / \mathrm{L})$ in Norway but are generally very low [9]. A recent review of vitamin D deficiency in central Europe has concluded that $25(\mathrm{OH}) \mathrm{D}$ levels are on average below $30 \mathrm{ng} / \mathrm{mL}$ [10]. Worldwide, it is estimated that one billion people have vitamin D deficiency [11], and it affects more than $40 \%$ of US and European men and women [12]. This high prevalence has also been reported in a Swiss study that has calculated a population-based estimation of vitamin $\mathrm{D}$ deficiency according to $25(\mathrm{OH}) \mathrm{D}$ serum levels, reporting that $39.5 \%$ of the population has $25(\mathrm{OH}) \mathrm{D}$ levels of $<20 \mathrm{ng} / \mathrm{mL}(<50 \mathrm{nmol} / \mathrm{L})$ (vitamin $\mathrm{D}$ deficiency) [13].

Of course, the prevalence of vitamin D deficiency and insufficiency depends on the definition used. Several definitions of vitamin $\mathrm{D}$ deficiency exist, some of which are presented in Table 1 . The reasons for the differences in these definitions are partially due to the outcomes, for which the defined cutoff levels were different (e.g., bone fracture, parathyroid hormone (PTH) level, cardiovascular (CV) events, and cancer). Obviously, it is very unlikely that the risks of these outcomes all increase at the same $25(\mathrm{OH}) \mathrm{D}$ level. Given the wide variation in the definitions of vitamin $\mathrm{D}$ deficiency, Pilz et al. have suggested that the ideal 25(OH)D concentration for overall health-related outcomes ranges from $40 \mathrm{nmol} / \mathrm{L}$ to $120 \mathrm{nmol} / \mathrm{L}$ [14]. In fact, a more accurate 
TABLE 1: Examples of different vitamin D status definitions.

\begin{tabular}{|c|c|c|c|c|c|c|c|}
\hline \multicolumn{2}{|c|}{ Mayo clinic } & \multicolumn{2}{|c|}{ Institute of Medicine (IOM) } & \multicolumn{2}{|c|}{ Pilz et al. } & \multicolumn{2}{|c|}{$\begin{array}{l}\text { Kidney Disease Improving } \\
\text { Global Outcomes (KDIGO) }\end{array}$} \\
\hline \multicolumn{2}{|c|}{ PMID*: 20675513} & \multicolumn{2}{|l|}{ PMID $^{*}: 21118827$} & \multicolumn{2}{|c|}{ PMID* $^{*}: 21682758$} & \multicolumn{2}{|c|}{ PMID*: 19644521} \\
\hline Severe deficiency & $<25$ & At risk of deficiency & $<30$ & Deficiency & $<50$ & Deficiency & $<37$ \\
\hline Moderate deficiency & $25-59.9$ & At risk of inadequate level & $30-49$ & Insufficiency & $50-74.9$ & Insufficiency & $37-75$ \\
\hline Optimal & $60-200$ & Sufficient & $50-125$ & Optimal & $75-100$ & Adequate & $>75$ \\
\hline \multirow[t]{2}{*}{ Possible toxicity } & $>200$ & Possible toxicity & $>125$ & Sufficiency & $75-250$ & & \\
\hline & & & & Intoxication & $>375-500$ & & \\
\hline
\end{tabular}

25(OH)D expressed in nmol/L. Conversion factor for 25(OH)D: $1 \mathrm{ng} / \mathrm{mL}=2.496 \mathrm{nmol} / \mathrm{L} ;{ }^{*}$ PMID: PubMed unique identification number.

range seems to be between 40 and $80 \mathrm{nmol} / \mathrm{L}$ according to a recent study that has suggested the presence of a J-curve between vitamin D level and overall mortality [15]. Debates on the ideal vitamin $\mathrm{D}$ concentration have increased after the publishing of the 2011 Institute of Medicine (IOM) report [16]. The IOM suggested that a lower $25(\mathrm{OH}) \mathrm{D}$ level should be used to define vitamin D deficiency and that a $25(\mathrm{OH}) \mathrm{D}$ serum level of $20 \mathrm{ng} / \mathrm{mL}$ ( $50 \mathrm{nmol} / \mathrm{L}$ ) is desirable for bone and overall health [16]. While vitamin $\mathrm{D}$ deficiency defined as a serum $25(\mathrm{OH}) \mathrm{D}$ level of $<20 \mathrm{ng} / \mathrm{mL}(50 \mathrm{nmol} / \mathrm{L})$ and vitamin $\mathrm{D}$ insufficiency defined as a $25(\mathrm{OH}) \mathrm{D}$ level of between 20 and $29 \mathrm{ng} / \mathrm{mL}$ (50-75 nmol/L) have been extensively used in epidemiological studies, the definition of vitamin $\mathrm{D}$ insufficiency is more controversial. Of note, a 25(OH)D level of at least $20 \mathrm{ng} / \mathrm{mL}(50 \mathrm{nmol} / \mathrm{L})$ was chosen by the IOM, with recommended dietary allowances of $600 \mathrm{IU} /$ day of vitamin $\mathrm{D}$ for individuals aged 1-70 years and $800 \mathrm{IU} /$ day for those aged 71 years and older to meet the requirements of at least 97.5\% of the population. Yet other definitions of vitamin $\mathrm{D}$ deficiency and insufficiency are proposed in the Kidney Disease Improving Global Outcomes (KDIGO) guidelines [17]; serum levels of vitamin $\mathrm{D}$ are considered as adequate when the concentration of $25(\mathrm{OH}) \mathrm{D}$ is higher than $30 \mathrm{ng} / \mathrm{mL}$, levels between $15-30 \mathrm{ng} / \mathrm{mL}$ are considered as insufficient, and values that are lower than $15 \mathrm{ng} / \mathrm{mL}$ define the diagnosis of vitamin $\mathrm{D}$ deficiency (Table 1 ).

Several factors have been proposed to explain the high prevalence of vitamin $\mathrm{D}$ deficiency, one of which is inadequate vitamin $\mathrm{D}$ intake [18]. Using data from a 10-year trend study (1999-2009, $N=9,320)$ performed in Geneva, Switzerland, de Abreu et al. have found that slightly more than $10 \%$ of participants complied with dietary recommendations for vitamin D intake [19]. This finding was in line with data suggesting that vitamin $\mathrm{D}$ is one of the critical vitamins and that its intake is below the recommended level $[18,20]$. This chronic insufficient intake of micronutrients in a population without the emergence of immediate clinical signs is typical of "Hidden Hunger" [20, 21].

2.1.2. Latitude and Season. Vitamin D is often presented as the link explaining most of the observed correlations between latitude and season with extraskeletal complications. Most vitamin D is produced in the skin from 7dehydrocholesterol by sunlight UVB exposure, which varies with latitude and season [3]. UVB exposure decreases from the equator towards the polar regions [22]. At approximately $0^{\circ}$ latitude (i.e., the equator, e.g., the Republic of Seychelles), a high level of vitamin D-effective UV radiation is present, which varies only slightly throughout the year. On the other hand, at approximately $40^{\circ}$ latitude (e.g., Switzerland, with a latitude of $47^{\circ}$ ), the level of vitamin D-effective UV radiation varies greatly throughout the year and decreases substantially during the winter [23].

Ecological studies have reported an inverse correlation of ischemic heart disease with sunlight and a seasonal pattern of coronary heart disease mortality [24]. We contributed to the largest ( $N=230,000$ from 15 countries) and most comprehensive (body mass index, waist circumference, blood pressure, total high- (HDL) and low-density lipoprotein (LDL) cholesterol, triglycerides, and glucose levels) study ever conducted to assess the seasonality of cardiovascular risk factors [25]. The results have strongly suggested that cardiovascular risk factors present a seasonal pattern, with lower levels occurring during the summer and higher levels during the winter, suggesting that at least part of the patterning might be due to changes in air/outdoor temperature, air pollution, and exposure to sunlight and thus differences in vitamin D levels [25].

Geographic and seasonal patterns of cancer incidence and mortality have also been reported in ecological studies [26, 27], suggesting a correlation between sunlight exposure (and, thus, vitamin D) and cancer.

2.2. VDR Receptor, VDR Gene, and Extrarenal 1-AlphaHydroxylase. The wide distribution of VDRs in humans, the influence of vitamin $\mathrm{D}$ on more than $3 \%$ of the human genome, and the extrarenal presence of 1-alpha-hydroxylase are often presented as factors explaining the very broad influence of vitamin D on health and disease [20].

Several biological systems have VDRs and are responsive to vitamin D. Because one of the major biological functions of this vitamin is to maintain calcium homeostasis, typical responses occur in the intestines and kidneys, which is where 1,25(OH)2D-VDR regulates genes, leading to increased calcium and phosphate absorption. Another typical action of vitamin $\mathrm{D}$ is the suppression of $\mathrm{PTH}$ synthesis by $1,25(\mathrm{OH}) 2 \mathrm{D}-\mathrm{VDR}$ in the parathyroid glands. However, a recent study has reported that the $1,25(\mathrm{OH}) 2 \mathrm{D}-\mathrm{VDR}$ complex controls the expression of genes and syntheses of mRNAs that are unrelated to calcium homeostasis. In fact, one of the reasons for the recent growing interest in the role of vitamin $\mathrm{D}$ in extraskeletal complications is emerging evidence that 
VDRs are largely distributed throughout human tissues. The list of tissues in which VDRs are distributed includes the hepatogastrointestinal system (e.g., the colon), the respiratory system (e.g., the lungs), the central nervous system (e.g., neurons), the cardiovascular system (e.g., cardiomyocytes), and the kidneys [28]. Thus, tissue and cellular VDR distribution is wide. Most human tissues and cell types are responsive to $1,25(\mathrm{OH}) 2 \mathrm{D}[29,30]$. For example, the vitamin D-VDR complex controls the expression of genes involved in the inhibition of the renin-angiotensin system (RAS), which influences blood pressure, as well as genes that promote the secretion of insulin and cell proliferation and differentiation [31-34].

VDR abundance and activity seem to play important roles in individual responses to $1,25(\mathrm{OH}) 2 \mathrm{D}$. Some VDR abundance and activity are determined by VDR polymorphisms (i.e., genetic variations that occur at a frequency of $>1 \%$ [35]) [5]. The VDR gene lies on chromosome 12 [36]. The coding sequence of the VDR protein is comprised of eight exons, and several (>60) genetic polymorphisms have been identified $[5,37]$. These polymorphisms may alter transcriptional activity and thus VDR abundance and may modulate cellular responsiveness to $1,25(\mathrm{OH}) 2 \mathrm{D}$. In particular, there is a polymorphic site at the $5^{\prime}$ end of the VDR gene Fok $I$ C/T. This polymorphism, in contrast with the other $V D R$ variants, results in an altered amino acid sequence $[5,37]$. The Fok $I$ $\mathrm{C}$ allele generates a shorter VDR protein than the $\mathrm{T}$ allele, and this shorter protein is thought to be more active than the longer one [5]. Another important polymorphism is the $C d x 2$ $V D R$ polymorphism, which is located in the promoter region of the $V D R$ gene in exon 1 . The $C d x 2 V D R$ polymorphism has been associated with VDR transcriptional activity in the intestinal tract. The $\mathrm{T}$ allele has shown up to $70 \%$ greater transcriptional activity compared with the C allele [38].

It was first estimated that the number of primary $1,25(\mathrm{OH}) 2 \mathrm{D}$ target genes is in the order of $100-500$ per tissue, but there seems to be many more genomic VDR binding sites per cell type (between 1000 and 10,000) [29]. However, as stressed by Carlberg, some of these sites may not have specific functions and may only represent noise [29].

The observations that extrarenal $1,25(\mathrm{OH}) 2 \mathrm{D}$ can also be produced (extrarenal 1-alpha-hydroxylase) and that $1,25(\mathrm{OH}) 2 \mathrm{D}$ can act locally in the tissues where it is produced (autocrine/paracrine activities) also support the potential role of vitamin D in extraskeletal complications [39].

2.3. Evidence from Molecular and Animal Studies. Molecular and animal studies have established associations of vitamin D with extraskeletal complications. Given the abundance of available literature on this topic, we will briefly present some major mechanisms involved in specific but frequent chronic extraskeletal complications, namely, CV disease (CVD) (high blood pressure, coronary heart disease, and stroke), type II diabetes, cancer, and chronic kidney disease (CKD).

2.3.1. Cardiovascular Disease: High Blood Pressure and Coronary Heart Disease. Molecular evidence has revealed effects of $1,25(\mathrm{OH}) 2 \mathrm{D}$ on blood pressure-related mechanisms [34]. These mechanisms include the direct inhibition by
$1,25(\mathrm{OH}) 2 \mathrm{D}$ of the RAS. VDR is expressed in the juxtaglomerular apparatus and modulates renin synthesis. Mice lacking VDRs are hyperreninemic and present with high blood pressure and cardiac hypertrophy [40]. By contrast, the overexpression of VDR in the mouse juxtaglomerular apparatus leads to hyporeninemia [41]. In addition, vitamin $\mathrm{D}$ can regulate blood pressure through the prevention of secondary hyperparathyroidism [42], and it seems to have a direct effect on vascular cells and endothelial function [43].

Different mechanisms have been proposed to explain the association of vitamin $\mathrm{D}$ with coronary heart disease [44], some of which are indirect. Vitamin D could be related to coronary heart disease by affecting blood pressure, glycemic control, or PTH. Other proposed mechanisms are more directly related to atherosclerosis, cardiac tissues, and vasculature. Animal studies have highlighted the roles of vitamin $\mathrm{D}$ in cardiomyocyte remodeling in response to injury and atherosclerosis as well as in cardiac relaxation and contractility [45]. Serum levels of vitamin D seem to be inversely associated with the extent of vascular calcification in individuals at risk of ischemic heart disease $[44,46]$. Vitamin $\mathrm{D}$ could confer protection against atherosclerosis and vascular calcification by directly affecting vascular smooth muscle cells (VSMCs). This vitamin causes an acute influx of calcium in VSMCs that might inhibit their proliferation [47]. Vitamin $\mathrm{D}$ could also be associated with coronary heart disease by downregulating proinflammatory cytokines (e.g., TNF- $\alpha$ and IL-6) and upregulating the anti-inflammatory cytokine IL-10 [44].

2.3.2. Type II Diabetes and Cancer. There is great interest in the roles of vitamin D in the susceptibilities of type II diabetes and metabolic syndrome [47]. The effects of vitamin D on type II diabetes could be mediated by its role in pancreatic $\beta$-cell function, insulin resistance, or inflammation $[33,48-$ 50]. With respect to cancer, studies using animal models have shown that knocking out VDR induces many types of cancers, including mammary, prostate, and colon cancers $[26,51]$. Recently, a low vitamin $\mathrm{D}$ level has even been proposed as a modulator of the link between diabetes and cancer [52].

2.3.3. Chronic Kidney Disease. CKD is defined as the persistence for 3 or more months of structural and/or functional abnormalities of the kidney [53]. CKD is associated with an increased risk of ischemic heart disease, stroke, peripheral vascular disease, anemia, bone disease, end-stage renal disease, and mortality. Mechanisms (beyond those related to parathormone or calcium) by which vitamin $\mathrm{D}$ might be associated with CKD are summarized in Figure 2. Vitamin $\mathrm{D}$ insufficiency correlates with mortality risk among patients with CKD and evidence has been reviewed elsewhere [54, 55]. For example, a recent meta-analysis of 20 observational studies showed vitamin D treatment to be associated with decreased risk of all-cause and cardiovascular mortality in patients with CKD not requiring dialysis and patients with end stage renal disease (ESRD) requiring dialysis [55]. This meta-analysis also highlighted the need of well-designed randomized controlled trials to formally assess the survival benefits of vitamin $\mathrm{D}$. 


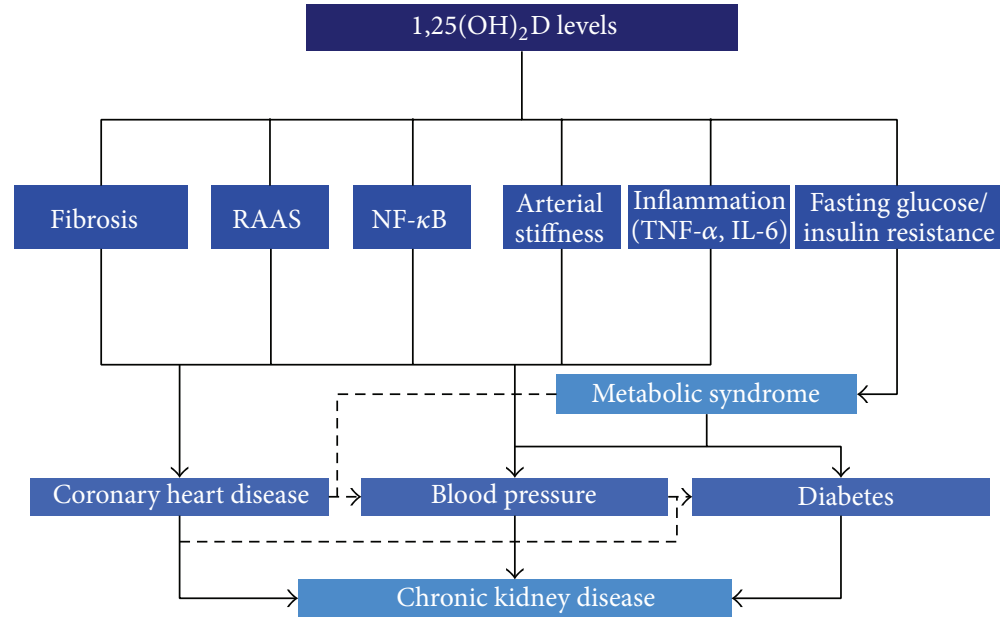

Figure 2: Main hypothetical mechanisms of action of vitamin D in chronic kidney disease. Mechanisms related to parathormone and calcium are not displayed. VSMC = vascular smooth muscle cells; RAAS = renin-angiotensin-aldosterone system; NF- $\kappa \mathrm{B}=$ nuclear factor- $\kappa \mathrm{B} ; \mathrm{TNF}-\alpha$ $=$ tumor necrosis factor- $\alpha$; IL- $6=$ interleukin -6 .

One of the mechanisms associating vitamin $\mathrm{D}$ with $\mathrm{CKD}$ involves the nuclear factor $-\kappa \mathrm{B}(\mathrm{NF}-\kappa \mathrm{B})$ pathway. $\mathrm{NF}-\kappa \mathrm{B}$ is a family of transcription factors that functions as a master regulator of the immune response [56]. It regulates a wide range of genes involved in inflammation, proliferation, and fibrogenesis and is known to have a key role in kidney disease [57]. A direct inhibition by $1,25(\mathrm{OH}) 2 \mathrm{D}$ of the $(\mathrm{NF}-\kappa \mathrm{B})$ pathway has been reported. Both RAS and NF- $\kappa$ B promote the production of profibrotic and proinflammatory factors, increase oxidative stress, and damage podocytes.

2.4. Evidence from Observational Studies. Guessous et al. have previously reviewed evidence of the roles of vitamin $\mathrm{D}$ in hypertension, coronary heart disease, and stroke [34]. Out of four observational prospective studies identified, two have reported an inverse association between $25(\mathrm{OH}) \mathrm{D}$ level and hypertension risk, one found no such association, and one found an association neither with hypertension nor with changes in blood pressure. Lower vitamin D levels have been found to be associated with an increased risk of myocardial infarction in a prospective study of men aged $40-75$ years [58]. Higher levels of 1,25(OH)D have been associated with decreased risk of stroke among participants in a cohort study conducted in Finland [59].

\subsection{Economic Impact of Correcting Vitamin D Deficiency.} Finally, a potentially huge economic benefit resulting from the correction (at the population level) of vitamin D deficiency is often presented. Assuming that vitamin D deficiency is causally associated with extraskeletal complications, it has been suggested that a rise in the serum 25(OH)D levels of all Europeans to $40 \mathrm{nmol} / \mathrm{L}$ (achieved by a daily intake of 2000-3000 IU of vitamin D) would lower health-care costs by up to $17 \%$, which represents a reduction of 187,000 million Euros/year [20,60]. Thus, a single, simple intervention could have a major impact on the economy of health care. However, this belief is conditional on a causal relationship of vitamin
D with extraskeletal complications that is far from being accepted as described below.

\section{Hypothesis \#2: Vitamin D Is Not Causally Associated with Extraskeletal Complications}

The belief that vitamin D is not causally associated with extraskeletal complications is mainly based on the absence of robust evidence of this association from randomized controlled trials (RCTs), on the potentially unfavorable effects of vitamin D supplementation and on the precedents of other vitamin and antioxidant trials.

3.1. Randomized Controlled Trials. To date, most associations of vitamin D with extraskeletal complications reported by nonexperimental studies have not been replicated in RCTs. For example, results from observational cross-sectional and prospective studies on the inverse association of vitamin D intake or $25(\mathrm{OH}) \mathrm{D}$ level with blood pressure have not been confirmed in RCTs [34]. Only one out of three RCTs identified have found a decrease in blood pressure in the intervention arm, but daily supplementation included both vitamin $\mathrm{D}_{3}$ and calcium (not vitamin $\mathrm{D}$ only) [61]. Two RCTs primarily designed to determine the effect of vitamin $\mathrm{D}$ supplementation on the risk of fracture have reported conflicting effects of this vitamin on coronary heart disease $[62,63]$, and no RCT has evaluated the effect of vitamin $\mathrm{D}$ supplementation on coronary heart disease as a primary outcome. Trivedi et al. have found no effect of vitamin D supplementation on stroke [62].

To evaluate the presence of biases in the associations of vitamin D with diverse skeletal and extraskeletal outcomes, Theodoratou et al. have performed a review of evidence obtained from systematic reviews and observational metaanalyses and RCTs (i.e., an umbrella review) [64]. More than 260 systematic reviews or meta-analyses that have included over 130 outcomes have been examined. This group has reported a lack of highly convincing evidence of a clear link of 
vitamin D with any outcome. Even for skeletal complications, the authors have concluded that RCTs that examined vitamin D only (without calcium supplementation) have failed to demonstrate protective effects of vitamin D supplementation on fractures or falls. Moreover, a 2014 trial sequential metaanalysis (i.e., analysis that modeled the changing precision in estimates of effects as trials are reported and the likely effects of future trial results on the existing body of data) has shown that the effects of vitamin D supplementation on extraskeletal complications are below the futility boundary of $15 \%[65,66]$. Thus, future trials are unlikely to alter the conclusion of no causal association.

A 2009 narrative review has estimated that raising the minimum year-round serum $25(\mathrm{OH}) \mathrm{D}$ level to $100-$ $150 \mathrm{nmol} / \mathrm{L}$ ( 40 to $60 \mathrm{ng} / \mathrm{mL}$ ) would prevent approximately 58,000 new cases of breast cancer and 49,000 new cases of colorectal cancer each year in the US and Canada [67]. However, the most recent (2011) meta-analysis has concluded that because of the potential confounding data inherent in observational studies and the limited data obtained from RCTs, evidence is currently insufficient to draw conclusions about the efficacy of vitamin D supplementation for cancer prevention [68]. A 2014 review of vitamin D status and CVD by the UK Nutrition Society has concluded that data supporting a causal link between vitamin D status and CVD are mixed and ambiguous [69]. Similar conclusions were independently published in 2011 by the North American DRI committee [16], by the Endocrine Task Force [70], and more recently, by others $[65,71-74]$. In terms of endocrine health and disease, available evidence does not show that vitamin D supplementation consistently decreases the risk of type II diabetes, Addison's disease, or autoimmune thyroid disease [75].

In a 2014 meta-analysis of observational studies $(N=73)$ and RCTs $(N=22)$ of vitamin $\mathrm{D}$ and mortality caused by extraskeletal complications, Chowdhury et al. have found evidence that $25(\mathrm{OH}) \mathrm{D}$ level is inversely associated with risk of death due to extraskeletal complications, but no evidence of such a relationship has been found in RCTs [76]. Stratified analysis has suggested that supplementation with vitamin $\mathrm{D}_{3}$ and not $\mathrm{D}_{2}$ reduces all-cause mortality [76], but most of the trials included in the stratified analysis reported a high score for the risk of bias.

Overall, the conclusions of the meta-analyses and reports are in contrast with other recent reviews, which have concluded that adequate vitamin D supplementation is an important prophylactic factor for immunity, autoimmunity, CVD, cancer, fertility, pregnancy, dementia, and mortality [77]. Therefore, most scientists have acknowledged that the prevalence of vitamin D deficiency is high (although as discussed above, the definition of vitamin D normality is not universal); however, based on the lack of robust evidence, some have questioned whether it is a health problem [78].

3.2. Unfavorable Effects of Vitamin D. Vitamin D may have unfavorable effects. For example, it could potentially contribute to arterial stiffening and hypertension. Richart et al. [79] have proposed mechanisms of the renal versus extrarenal activation of vitamin $\mathrm{D}$ in relation to atherosclerosis, arterial stiffening, and hypertension. Macrophages in atherosclerotic lesions can locally activate $25(\mathrm{OH}) \mathrm{D}$ to form calcitriol, which could act as a vasoactive and prooxidative substance in VSMCs. Another concern is related to severe cases of hypercalcemia observed in children with CYP24A1 mutations [80]. Concerns extend beyond extraskeletal complications because recent evidence has also suggested that high doses of vitamin D may increase the risks of fractures and falls [81, 82].

3.3. Vitamins, Antioxidants, and Hormone Replacement Therapy Precedents. Skepticism about the curative and/or predictive potentials of vitamin $\mathrm{D}$ for extraskeletal complications has also been magnified by previous vitamin-related research, in which evidence reported in observational studies has not been replicated in RCTs [83]. RCTs of beta-carotene, vitamin $\mathrm{A}$, and vitamin $\mathrm{E}$ have not replicated findings from observational studies [84]. Even worse, RCTs have reported that some antioxidants and vitamins with supposed favorable effects (based on observational studies) in fact have unfavorable effects (based on RCTs). In 2008, the SELECT trial of vitamin $\mathrm{E}$ and selenium in cancer prevention was stopped prematurely because the intervention arm was more (although not statistically significantly) likely to develop prostate cancer [85]. This, of course, echoes the experience and lessons learned from the Women's Health Initiative (WHI) study on hormone replacement therapy (HRT) [86]. This trial was stopped prematurely when an increase in invasive breast cancer achieved statistical significance. This trial also found increases in heart attacks and strokes in the intervention group. These findings contrasted dramatically with conclusions of previous epidemiologic studies, which indicated a lack of a convincing link between breast cancer and HRT and reported that HRT decreases cardiovascular events [87].

\section{Issues Favoring One Hypothesis over the Other}

4.1. Causality. A major point in the debate about the real impact of vitamin D deficiency on extraskeletal complications is whether $25(\mathrm{OH}) \mathrm{D}$ belongs to the causal pathway. In other words, does a low 25(OH)D level cause disease or is it simply a side effect of either the exposure (e.g., sedentary behavior or obesity) or disease (e.g., cancer or autoimmune disease)? While an RCT (i.e., the supreme paradigm for epidemiological research [88]) is the best study design to determine causality, risk factors, such as low 25(OH)D levels, cannot be assessed with this type of trial for obvious ethical reasons. Observational studies, which are prone to spurious results, are then conducted. This issue of study design is so central that some epidemiologists have categorized the field into descriptive problems (i.e., a parameter of occurrence is related to a determinant without a causal interpretation of the relationship) and causal problems [88]. A causal interpretation of the relationship of an outcome parameter (type II diabetes) to a determinant $(25(\mathrm{OH}) \mathrm{D})$ can be given as long as the relationship is conditional on the entire set of potential confounders (both known and unknown). This 
requisite conditionality is best pursued by randomization [88] and thus the use of RCTs.

4.2. Confounding and Reverse Causation. Confounding happens when the effect of at least one extraneous factor (e.g., body mass index, BMI) is mixed with the effect of an exposure of interest $(25(\mathrm{OH}) \mathrm{D})$, thus distorting the estimate of the latter [89]. With respect to vitamin $\mathrm{D}$, the list of potential known confounders is very large and includes the following major ones. (1) Age: the production of vitamin $\mathrm{D}$ by the skin decreases with age [2]. (2) BMI: the reasons for the inverse association between $\mathrm{BMI}$ and $25(\mathrm{OH}) \mathrm{D}$ level are not completely understood, but fat in the skin seems to decrease the efficacy of vitamin $\mathrm{D}$ synthesis, which may be due to 7-dehydrocholesterol sequestration. Of note, this inverse association could also be confounded by a decrease in sun exposure (e.g., a decrease in outdoor physical activity or comorbidities). (3) Latitude and seasons: theoretically, persons living in regions closer to the equator should present with higher levels of vitamin $\mathrm{D}$ synthesis than those residing in regions remote from the equator. In practice, however, because more than $90 \%$ of vitamin D arises from sunlight (in the absence of supplementation), levels of this vitamin also depend on cultural behaviors (clothing, time spent outdoors, and sunbathing habits). Overall, reports of the effect of latitude on serum 25(OH)D have been inconsistent [90-92]. A positive correlation between $25(\mathrm{OH}) \mathrm{D}$ and latitude has been found in a (25 European countries) pooled analysis, whereas the highest rate of $25(\mathrm{OH}) \mathrm{D}$ deficiency has been observed in Scottish participants (highest latitude) in a British crosssectional study [91]. However, recent metaregression analysis did not find an influence of latitude on 25(OH)D level [92]. (4) Skin pigmentation: the packaging and sizes of melanosomes in keratocytes influence the darkness of the skin. Dark pigments in the skin reduce its ability to synthesize vitamin $\mathrm{D}$ from sunlight by up to $95 \%$ [22]. This fact likely explains why African-Americans have lower 25(OH)D than non-Hispanic whites in the US [22]. The darker skin pigmentation in individuals residing in southern compared to northern European countries may underlie the higher prevalence of 25(OH)D deficiency in southern Europe [93]. (5) Diet: diets typically contain only small amounts of vitamin $\mathrm{D}$ (vitamin $\mathrm{D}_{3}$ or vitamin $\mathrm{D}_{2}$ ). Fish is the major dietary source of vitamin D in humans. Three ounces of cooked salmon and 3.5 ounces of cooked mackerel provide $90 \%$ and $86 \%$, respectively, of the recommended daily vitamin D intake (400-600 international units/day), whereas 3.5 ounces of cooked beef only provides $4 \%$ of the recommended intake. (6) Occasional sunscreen: sunscreen use by children and young adults is unlikely to cause vitamin D deficiency, but the chronic use of sunscreen by elderly individuals has been shown to decrease $25(\mathrm{OH}) \mathrm{D}$ and to cause vitamin $\mathrm{D}$ deficiency. (7) Altitude, air pollution, ozone, time of the day, and cloud cover: at higher altitudes, UVB radiation is stronger because the concentrations of aerosols and particles are lower. Air pollution decreases vitamin D-effective radiation. Ozone, time of the day, and cloud cover also influence vitamin D-effective radiation and thus vitamin $\mathrm{D}$ photosynthesis. Other potential confounders include genetic and epigenetic (i.e., heritable and modifiable changes in gene expression that do not affect DNA sequences) variations that have been implicated in association with vitamin $\mathrm{D}$ that may contribute to the interindividual variability of the impacts of its deficiency and/or supplementation $[29,94]$. Disregarding the unknown potential confounders, fully accounting for all of these potential known confounders is practically impossible (residual confounding) unless randomization is used.

Temporality in causal criteria refers to the necessity that the cause precedes the effect in time (causal sequence) [89]. Thus, reverse causation refers to a situation in which an outcome precedes and causes an exposure instead of the other way around [95]. Autier et al. have performed a systematic review of vitamin $\mathrm{D}$ status and ill health and have concluded that the discrepancies between observational and intervention studies indicate that low $25(\mathrm{OH}) \mathrm{D}$ is a marker, not a cause, of ill health [96]. These authors have notably proposed that the wide range of disorders associated with low $25(\mathrm{OH}) \mathrm{D}$ is explained by the fact that inflammatory processes involved in disease occurrence and clinical course reduce $25(\mathrm{OH}) \mathrm{D}$. Other groups have stressed that $25(\mathrm{OH}) \mathrm{D}$ is an unreliable biomarker of vitamin $\mathrm{D}$ status after an acute inflammatory insult [97].

Although subgroup analysis of a recent meta-analysis of observational studies has suggested that the inverse association of $25(\mathrm{OH}) \mathrm{D}$ level with mortality is stronger in populations with low prevalences of vitamin $\mathrm{D}$ supplementation or low 25(OH)D levels [76], this finding can still be attributed to reverse causation, with more severe underlying diseases being associated with lower 25(OH)D levels.

4.3. Mendelian Randomization. Randomization in observational studies is not possible, but an alternative exists, which is termed Mendelian randomization (MR). MR is being increasingly used to overcome confounding and reverse causation for exploring causal effects of an exposure on a disease in nonexperimental studies. The concept of MR refers to the random allocation of alleles at the time of gamete formation. By analogy with the fact that the random allocation of a treatment in a RCT renders confounding unlikely, a genetic variant of interest should not be associated with known and unknown confounding factors [98, 99]. MR studies have been conducted to infer causality for vitamin D and extraskeletal complications, such as high blood pressure and type II diabetes. Genetic variants that specifically alter $25(\mathrm{OH}) \mathrm{D}$ levels, which are usually identified from genomewide association studies (GWAS), are generally used. For example, Kunutsor et al. have used 4 variants (in the DHCR7, CYP2R1, GC, and CYP24A1 genes) as instrumental variables in a small sample (unknown $N$ ), failing to show a causal role of $25(\mathrm{OH}) \mathrm{D}$ in the etiology of high blood pressure [100]. Vimaleswaran et al. have used the same 4 variants but have considered allelic scores and used a large sample $(N=146,581)$, reporting that each $10 \%$ increase in genetically instrumented $25(\mathrm{OH}) \mathrm{D}$ concentration is associated with an $8 \%$ decreased odds of hypertension [101]. Using the same 
variants as mentioned above but not considering allelic scores, Ye et al. have also estimated the unconfounded causal associations of $25(\mathrm{OH}) \mathrm{D}$ concentration with the risks of type II diabetes and other glycemic traits using an MR approach [102], reporting insignificant MR-derived estimates for type II diabetes and glycemic traits and suggesting that the association between $25(\mathrm{OH}) \mathrm{D}$ and type 2 diabetes is not causal.

Of note, there are commonly acknowledged necessary conditions for MR to provide a causal inference in observational epidemiology $[98,99]$. One condition is that the genetic instruments (e.g., DHCR7 variants) affect the outcome (e.g., extraskeletal complication) by no other means than through the exposure $(25(\mathrm{OH}) \mathrm{D})$, which is never the case with respect to common complex human diseases. Additionally, one cannot exclude that a true causal variant may be in linkage disequilibrium with the genetic instruments (genetic variants) used. Results obtained using the MR approach should therefore be interpreted cautiously.

\subsection{Measurement Error and Misclassification}

4.4.1. Is 25(OH)D a Good Biomarker of Vitamin D Intake and/or Function? 1,25(OH)2D is the active form of vitamin $\mathrm{D}$, but because $25(\mathrm{OH}) \mathrm{D}$ has a much longer circulating halflife, circulates at higher concentrations, and is less influenced by other hormones, such as $\mathrm{PTH}$, it is used to determine vitamin D status. Because of its long half-life in circulation, $25(\mathrm{OH}) \mathrm{D}$ reflects vitamin $\mathrm{D}$ supply and usage over a period of time. Circulating $25(\mathrm{OH}) \mathrm{D}$ is also a better marker of vitamin $\mathrm{D}$ exposure than indirect estimates of vitamin $\mathrm{D}$ exposure based solely on diet, which do not take into consideration sunlight sources [103].

However, as discussed elsewhere [104], serum 25(OH)D concentration is influenced by several factors, such as the quantity of vitamin $\mathrm{D}$ delivered to the liver, the amount of $25(\mathrm{OH}) \mathrm{D}$ produced by the liver, and the half-life of $25(\mathrm{OH}) \mathrm{D}$ in the serum. These factors are themselves influenced by several determinants (sunlight exposure, intestinal absorption, body fat, 25-hydroxylase activity, VDBP production in the liver, etc.) [104]. Prentice et al. have stressed that because serum $25(\mathrm{OH}) \mathrm{D}$ has little interaction with VDRs, it might be a good biomarker of intake but not of function [104]. Therefore, other biomarkers of vitamin $\mathrm{D}$ function have been proposed (e.g., the $1,25(\mathrm{OH}) 2 \mathrm{D} / 25(\mathrm{OH}) \mathrm{D}$ ratio, $1,25(\mathrm{OH}) 2 \mathrm{D} / 24,25(\mathrm{OH}) 2 \mathrm{D}$ ratio, and $>35$ additional $25(\mathrm{OH}) \mathrm{D}$ metabolites formed by the body). However, evaluating such biomarkers in large epidemiological studies is difficult. Additionally, serial measurements in the same individuals are ideal but rarely feasible. Therefore, it is not excluded that $25(\mathrm{OH}) \mathrm{D}$, when used as a biomarker of extraskeletal complications, provides biased associations similar to many other biomarkers, as demonstrated in a recent systematic evaluation of 56 meta-analyses of emerging cardiovascular biomarkers (e.g., C-reactive protein and homocysteine) [105].

Even if we agree that $25(\mathrm{OH}) \mathrm{D}$ is sufficiently linked to active $1,25(\mathrm{OH}) \mathrm{D}$ and is the best marker of vitamin $\mathrm{D}$ status similar to the conclusion of a meta-analysis performed by
Tzoulaki et al. [105], it is worth noting that results vary markedly depending on the assay used [106, 107]. Liquid chromatography tandem mass spectrometry (LC-MS/MS) remains the gold standard technique to measure $25(\mathrm{OH}) \mathrm{D}$ $[106,108]$.

\subsection{Deficiency versus Supplementation and Life-Course Per-} spective. Different factors that could explain the lack of replication in the few RCTs of the results reported by several observational studies have been discussed. For example, it has been suggested that the impact of vitamin $\mathrm{D}$ deficiency (as determined in observational studies) is not the same as the effect of vitamin D supplementation (as determined in RCTs), particularly in participants with sufficient vitamin D levels [109]. Other groups have suggested that the relationship of $25(\mathrm{OH}) \mathrm{D}$ with the risk of extraskeletal complications could be observable only at low levels of $25(\mathrm{OH}) \mathrm{D}[26,109]$. Davis has also suggested that the risk associated with low vitamin $\mathrm{D}$ status might be conferred earlier in life and that studies of circulating $25(\mathrm{OH}) \mathrm{D}$ in adults do not address the most relevant time period of exposure [26]. Vitamin D may play pivotal roles throughout life not only in calcium homeostasis and skeletal metabolism but also in infection and autoimmune disease development and progression [104]. Reviews have been published on vitamin $\mathrm{D}$ and functional outcomes, specifically in infants and young children [110], adolescents [111], and elderly individuals [112].

\section{Why Results from Ongoing Randomized Controlled Trials Will Be Unlikely to Reconcile the Two Schools of Thought}

Five RCTs (the CAPS, VITAL, Do-Health, FIND, and ViDa trials; see [20] for further details) are currently underway in 9 countries (Figure 3 ) to determine the impacts of vitamin D supplementation on extraskeletal complications. Most are well funded and sufficiently powered to detect a significant impact, if any exist. More than 42,000 participants will be included with a potential of 208,116 person-years, and $\$ 22$ million has been invested just for the VITAL trial [113]. However, several experts have already pointed out fatal limitations that might invalidate the (negative or null) results of these trials $[69,114-117]$. These limitations include the following: (i) the supplementation doses of vitamin D are too low, and higher doses should be tested; (ii) the contrast in $25(\mathrm{OH}) \mathrm{D}$ intake between the two arms is insufficient given that control groups are producing $25(\mathrm{OH}) \mathrm{D}$ even in the absence of the intervention; (iii) the 5-year follow up (which some experts have attributed to be based more on the funding grant cycle than on the vitamin $\mathrm{D}$ cycle) is too short; (iv) the optimal vitamin $\mathrm{D}$ concentration may not be the same for all extraskeletal complications considered; (v) participants are included regardless of their $25(\mathrm{OH}) \mathrm{D}$ level at baseline, and most participants already have an optimal 25(OH)D level prior to the start of the intervention. The effects of vitamin $\mathrm{D}$ likely depend on the baseline vitamin D status; and (vi) future trials are not likely to change pooled (null) estimates already reported by meta-analyses. 


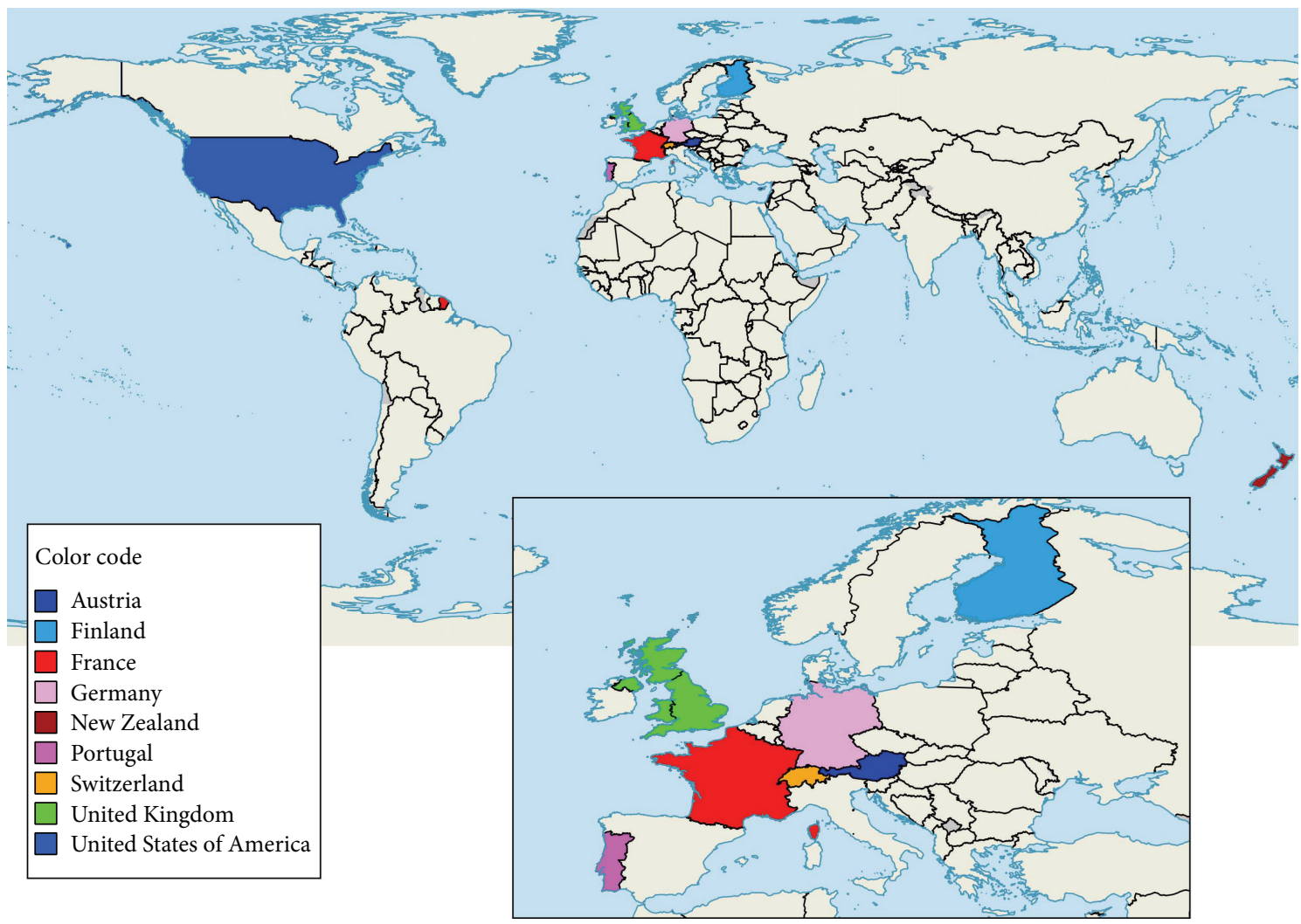

FIGURE 3: Countries where large randomized controlled trials are currently ongoing to determine the impact of vitamin D supplementation on extraskeletal complications. CAPS, USA; VITAL, USA; Do-Health, Austria, Germany, Finland, France, Portugal, Switzerland; FIND, Finland; ViDa; New Zealand. See [20] for further details.

We would like to add to these limitations the potential risk of "medical reversal," which is a phenomenon described by Prasad et al. involving the identification of faults with trials and the unwillingness to consider that an intervention might be ineffective [118]. We believe that medical reversal is even more likely to happen if ongoing trials report null effects (rather than negative effects, as in the WHI trial).

\section{Summary and Concluding Remarks}

This debate is mostly fueled by the classical divergence between observational and experimental results [119]. Observational studies are prone to reverse causation and confounding. Associations between vitamin D status and extraskeletal complications in observational studies could merely indicate that vitamin D is a "simple" indicator of health status and that compared with healthier subjects sicker subjects could have a lower vitamin $\mathrm{D}$ level or status. The diversity of biological systems with which vitamin $\mathrm{D}$ deficiency has been associated (cardiovascular, diabetes, depression, neurodegenerative diseases, cancer, etc.) could further suggest that this vitamin is a marker of health status rather than a predictor of health outcomes. However, both the wide distribution of VDRs in humans and the influence of vitamin D on more than $3 \%$ of the human genome could explain its broad effects on health.

RCTs assessing the efficacy of vitamin D supplementation in reducing extraskeletal complications are ongoing. Trials are still recruiting participants, and the first results will not be available before the year 2017. The impacts of the ongoing RCTs on clinical practice are of course difficult to predict, but at least three scenarios exist as follows: favorable and meaningful results are reported by the RCTs (scenario A); no favorable or meaningful results are reported (scenario B); or unfavorable results are reported (scenario C). All of these scenarios may or may not be followed by appropriate changes in clinical practice. Depending on the scenario, the baseline common practice, and the capacity of change in the common practice, the use of vitamin D as a biomarker could be a success or failure, as proposed by Ioannidis [120]. If it is not a success, vitamin D could eventually become a biomarker of the following: (i) "type B failure" occurs "when a biomarker shows great promise in one or more early studies, but the claims are later found to be wrong or exaggerated, and the biomarker is eventually never implemented into clinical practice" (scenario A in a practice, in which vitamin D dosing is not already common); (ii) "type D failure" occurs "when a biomarker shows no or little promise, but nevertheless is enthusiastically promoted for widespread clinical or population use" (scenario C in a practice, in which vitamin D dosing is already common); and (iii) "type A failure" occurs "when a widely used biomarker that has already been implemented in clinical practice is shown to be largely useless-or even harmful—and therefore needs to be abandoned" (scenario C 
in a practice, in which vitamin D dosing is already common but the common practice can be changed).

Determining $25(\mathrm{OH}) \mathrm{D}$ dosages in the absence of robust evidence seems to already be a common practice in the US, where sales of vitamin D supplements have increased from $\$ 50$ million in 2005 to $\$ 600$ million in 2011 [121] and where commentators already advocate clinicians to stop costly measurements of $25(\mathrm{OH}) \mathrm{D}$ in asymptomatic patients outside skeletal-related conditions $[83,122,123]$.

Finally, while our review focused on extraskeletal complications and discussed the related challenges, this debate might not remain limited to extraskeletal complications for long but may soon include skeletal complications. Indeed, recent evidence has suggested that vitamin $\mathrm{D}$ might not be as essential as previously thought for maintaining bone health and preventing falls $[64-66,124]$.

Vitamin D (the solar vitamin) is likely to remain a burning topic in coming years.

\section{Conflict of Interests}

The author declares that there is no conflict of interests regarding the publication of this paper.

\section{Acknowledgment}

This work was supported by the Swiss National Science Foundation (FN 33CM30-124087 and FN 33CM30-140331).

\section{References}

[1] M. Holick, "Evolution, biologic functions, and recommended dietary allowances for vitamin D," in Vitamin D: Molecular Biology, Physiology, and Clinical Applications: Nutrition and Health, Nutrition and Health, pp. 1-16, Humana Press, 1999.

[2] M. F. Holick, "McCollum Award Lecture, 1994: vitamin D-new horizons for the 21st century," The American Journal of Clinical Nutrition, vol. 60, no. 4, pp. 619-630, 1994.

[3] M. Wacker and M. F. Holick, "Sunlight and Vitamin D: a global perspective for health," Dermato-Endocrinology, vol. 5, no. 1, pp. 51-108, 2013.

[4] B. A. Gilchrest, "Sun exposure and vitamin D sufficiency," The American Journal of Clinical Nutrition, vol. 88, no. 2, pp. 570S577S, 2008.

[5] A. G. Uitterlinden, Y. Fang, J. B. J. van Meurs, H. A. P. Pols, and J. P. T. M. van Leeuwen, "Genetics and biology of vitamin D receptor polymorphisms," Gene, vol. 338, no. 2, pp. 143-156, 2004.

[6] D. Feldman, J. W. Pike, and J. S. Adams, Vitamin D, Academic Press, 2011.

[7] T.-T. Wang, L. E. Tavera-Mendoza, D. Laperriere et al., "Largescale in silico and microarray-based identification of direct 1,25dihydroxyvitamin D3 target genes," Molecular Endocrinology, vol. 19, no. 11, pp. 2685-2695, 2005.

[8] I. Schuster, "Cytochromes P450 are essential players in the vitamin D signaling system," Biochimica et Biophysica ActaProteins and Proteomics, vol. 1814, no. 1, pp. 186-199, 2011.

[9] N. M. van Schoor and P. Lips, "Worldwide vitamin D status," Best Practice \& Research: Clinical Endocrinology \& Metabolism, vol. 25, no. 4, pp. 671-680, 2011.
[10] P. Pludowski, W. B. Grant, H. P. Bhattoa et al., "Vitamin D status in central Europe," International Journal of Endocrinology, vol. 2014, Article ID 589587, 12 pages, 2014.

[11] M. F. Holick and T. C. Chen, "Vitamin D deficiency: a worldwide problem with health consequences," The American Journal of Clinical Nutrition, vol. 87, no. 4, pp. 1080S-1086S, 2008.

[12] M. F. Holick, "Vitamin D deficiency," The New England Journal of Medicine, vol. 357, no. 3, pp. 266-281, 2007.

[13] I. Guessous, V. Dudler, N. Glatz et al., "Vitamin D levels and associated factors: a population-based study in Switzerland," Swiss Medical Weekly, vol. 142, Article ID w13719, 2012.

[14] S. Pilz, A. Tomaschitz, W. März et al., "Vitamin D, cardiovascular disease and mortality," Clinical Endocrinology, vol. 75, no. 5, pp. 575-584, 2011.

[15] D. Durup, H. L. Jørgensen, J. Christensen, P. Schwarz, A. M. Heegaard, and B. Lind, "A reverse J-shaped association of allcause mortality with serum 25-hydroxyvitamin D in general practice: the CopD study," Journal of Clinical Endocrinology and Metabolism, vol. 97, no. 8, pp. 2644-2652, 2012.

[16] A. C. Ross, J. E. Manson, S. A. Abrams et al., "The 2011 report on dietary reference intakes for calcium and vitamin $\mathrm{D}$ from the Institute of Medicine: what clinicians need to know," Journal of Clinical Endocrinology and Metabolism, vol. 96, no. 1, pp. 53-58, 2011.

[17] "KDIGO clinical practice guideline for the diagnosis, evaluation, prevention, and treatment of Chronic Kidney DiseaseMineral and Bone Disorder (CKD-MBD)," Kidney International Supplements, no. 113, pp. S1-S130, 2009.

[18] B. Troesch, B. Hoeft, M. McBurney, M. Eggersdorfer, and P. Weber, "Dietary surveys indicate vitamin intakes below recommendations are common in representative Western countries," British Journal of Nutrition, vol. 108, no. 4, pp. 692-698, 2012.

[19] D. de Abreu, I. Guessous, J.-M. Gaspoz, and P. MarquesVidal, "Compliance with the Swiss society for nutrition's dietary recommendations in the population of Geneva, Switzerland: a 10-year trend study (1999-2009)," Journal of the Academy of Nutrition and Dietetics, vol. 114, no. 5, pp. 774-780, 2014.

[20] I. Bendik, A. Friedel, F. F. Roos, P. Weber, and M. Eggersdorfer, "Vitamin D: a critical and essential micronutrient for human health," Frontiers in Physiology, vol. 5, article 248, 2014.

[21] H. K. Biesalski, "International congress 'hidden hunger', March 5-9, 2013, Stuttgart-Hohenheim, Germany," Annals of Nutrition and Metabolism, vol. 62, no. 4, pp. 298-302, 2013.

[22] M. F. Holick, "Vitamin D: a millenium perspective," Journal of Cellular Biochemistry, vol. 88, no. 2, pp. 296-307, 2003.

[23] M. G. Kimlin, "Geographic location and vitamin D synthesis," Molecular Aspects of Medicine, vol. 29, no. 6, pp. 453-461, 2008.

[24] T. J. Wang, M. J. Pencina, S. L. Booth et al., "Vitamin D deficiency and risk of cardiovascular disease," Circulation, vol. 117, no. 4, pp. 503-511, 2008.

[25] H. Marti-Soler, C. Gubelmann, S. Aeschbacher et al., "Seasonality of cardiovascular risk factors: an analysis including over 230, 000 participants in 15 countries," Heart, vol. 100, no. 9, pp. 1517-1523, 2014.

[26] C. D. Davis, "Vitamin D and cancer: current dilemmas and future research needs," The American Journal of Clinical Nutrition, vol. 88, no. 2, pp. 565S-569S, 2008.

[27] C. L. Hanchette and G. G. Schwartz, "Geographic patterns of prostate cancer mortality. Evidence for a protective effect of ultraviolet radiation," Cancer, vol. 70, no. 12, pp. 2861-2869, 1992. 
[28] M. R. Haussler, "Vitamin D receptors: nature and function," Annual Review of Nutrition, vol. 6, pp. 527-562, 1986.

[29] C. Carlberg, "Genome-wide (over)view on the actions of vitamin D," Frontiers in Physiology, vol. 5, article 167, 2014.

[30] Y. Wang, J. Zhu, and H. F. DeLuca, "Where is the vitamin D receptor?" Archives of Biochemistry and Biophysics, vol. 523, no. 1, pp. 123-133, 2012.

[31] I. Guessous and M. Bochud, "Opposite impacts of dietary versus supplemental calcium on cardiovascular health," EvidenceBased Medicine, vol. 18, no. 3, pp. 113-114, 2013.

[32] I. Guessous and M. Bochud, "Effects of calcium and vitamin D supplementations on cardiovascular disease: review article," Revue Médicale Suisse, vol. 8, no. 348, pp. 1458-1463, 2012.

[33] H. Wasse, F. Cardarelli, C. de Staercke, C. Hooper, E. Veledar, and I. Guessous, "25-hydroxyvitamin D concentration is inversely associated with serum MMP-9 in a cross-sectional study of African American ESRD patients," BMC Nephrology, vol. 12, no. 1, article 24, 2011.

[34] I. Guessous, M. Bochud, O. Bonny, and M. Burnier, "Calcium, vitamin D and cardiovascular disease," Kidney and Blood Pressure Research, vol. 34, no. 6, pp. 404-417, 2011.

[35] T. A. Pearson and T. A. Manolio, "How to interpret a genomewide association study," The Journal of the American Medical Association, vol. 299, no. 11, pp. 1335-1344, 2008.

[36] D. P. McDonnell, D. J. Mangelsdorf, J. W. Pike, M. R. Haussler, and B. W. O'Malley, "Molecular cloning of complementary DNA encoding the avian receptor for vitamin D," Science, vol. 235, no. 4793, pp. 1214-1217, 1987.

[37] A. G. Uitterlinden, Y. Fang, J. B. J. van Meurs, H. van Leeuwen, and H. A. P. Pols, "Vitamin D receptor gene polymorphisms in relation to Vitamin D related disease states," Journal of Steroid Biochemistry and Molecular Biology, vol. 89-90, no. 1-5, pp. 187193, 2004.

[38] H. Arai, K.-I. Miyamoto, M. Yoshida et al., “The polymorphism in the caudal-related homeodomain protein $\mathrm{Cdx}-2$ binding element in the human vitamin D receptor gene," Journal of Bone and Mineral Research, vol. 16, no. 7, pp. 1256-1264, 2001.

[39] H. A. Morris and P. H. Anderson, "Autocrine and paracrine actions of vitamin D," The Clinical Biochemist Reviews, vol. 31, no. 4, pp. 129-138, 2010.

[40] W. Xiang, J. Kong, S. Chen et al., "Cardiac hypertrophy in vitamin D receptor knockout mice: role of the systemic and cardiac renin-angiotensin systems," The American Journal of Physiology-Endocrinology and Metabolism, vol. 288, no. 1, pp. E125-E132, 2005.

[41] J. Kong, G. Qiao, Z. Zhang, S. Q. Liu, and Y. C. Li, “Targeted vitamin $\mathrm{D}$ receptor expression in juxtaglomerular cells suppresses renin expression independent of parathyroid hormone and calcium," Kidney International, vol. 74, no. 12, pp. 1577-1581, 2008.

[42] S. Pilz, A. Tomaschitz, E. Ritz, and T. R. Pieber, "Vitamin D status and arterial hypertension: a systematic review," Nature Reviews Cardiology, vol. 6, no. 10, pp. 621-630, 2009.

[43] M. S. K. Wong, R. Delansorne, R. Y. K. Man, and P. M. Vanhoutte, "Vitamin D derivatives acutely reduce endotheliumdependent contractions in the aorta of the spontaneously hypertensive rat," The American Journal of Physiology-Heart and Circulatory Physiology, vol. 295, no. 1, pp. H289-H296, 2008.

[44] A. Zittermann, S. S. Schleithoff, and R. Koerfer, "Putting cardiovascular disease and vitamin D insufficiency into perspective," British Journal of Nutrition, vol. 94, no. 4, pp. 483-492, 2005.
[45] T. D. O’Connell, J. E. Berry, A. K. Jarvis, M. J. Somerman, and R. U. Simpson, "1,25-dihydroxyvitamin D3 regulation of cardiac myocyte proliferation and hypertrophy," The American Journal of Physiology-Heart and Circulatory Physiology, vol. 272, no. 4, part 2, pp. H1751-H1758, 1997.

[46] K. E. Watson, M. L. Abrolat, L. L. Malone et al., "Active serum vitamin D levels are inversely correlated with coronary calcification," Circulation, vol. 96, no. 6, pp. 1755-1760, 1997.

[47] S. Penckofer, J. Kouba, D. E. Wallis, and M. A. Emanuele, "Vitamin D and diabetes: let the sunshine in," Diabetes Educator, vol. 34, no. 6, pp. 939-954, 2008.

[48] A. G. Pittas, J. Lau, F. B. Hu, and B. Dawson-Hughes, "The role of vitamin $\mathrm{D}$ and calcium in type 2 diabetes. A systematic review and meta-analysis," Journal of Clinical Endocrinology and Metabolism, vol. 92, no. 6, pp. 2017-2029, 2007.

[49] K. Yin and D. K. Agrawal, "Vitamin D and inflammatory diseases," Journal of Inflammation Research, vol. 7, no. 1, pp. 6987, 2014.

[50] T. K. Wobke, B. L. Sorg, and D. Steinhilber, "Vitamin D in inflammatory diseases," Frontiers in Physiology, vol. 5, article 244, 2014.

[51] S. Mordan-Mccombs, M. Valrance, G. Zinser, M. Tenniswood, and J. Welsh, "Calcium, vitamin D and the vitamin D receptor: impact on prostate and breast cancer in preclinical models," Nutrition Reviews, vol. 65, no. 8, part 2, pp. S131-S133, 2007.

[52] S. Ahmad, T. A. Chowdhury, and B. J. Boucher, "Diabetes and cancer: could vitamin D provide the link?" Journal of Diabetes and Its Complications, vol. 27, no. 2, pp. 184-190, 2013.

[53] National Kidney Foundation, "K/DOQI clinical practice guidelines for chronic kidney disease: evaluation, classification, and stratification," The American Journal of Kidney Diseases, vol. 39, no. 2, supplement 1, pp. S1-S266, 2002.

[54] F. Duranton, M. E. Rodriguez-Ortiz, Y. Duny, M. Rodriguez, J. P. Daurès, and A. Argilés, "Vitamin D treatment and mortality in chronic kidney disease: a systematic review and meta-analysis," The American Journal of Nephrology, vol. 37, no. 3, pp. 239-248, 2013.

[55] Z. Zheng, H. Shi, J. Jia, D. Li, and S. Lin, "Vitamin D supplementation and mortality risk in chronic kidney disease: a meta-analysis of 20 observational studies," BMC Nephrology, vol. 14, article 199, 2013.

[56] G. Bonizzi and M. Karin, "The two NF-kappaB activation pathways and their role in innate and adaptive immunity," Trends in Immunology, vol. 25, no. 6, pp. 280-288, 2004.

[57] C. Guijarro and J. Egido, "Transcription factor- $\kappa \mathrm{B}(\mathrm{NF}-\kappa \mathrm{B})$ and renal disease," Kidney International, vol. 59, no. 2, pp. 415-424, 2001.

[58] E. Giovannucci, Y. Liu, B. W. Hollis, and E. B. Rimm, "25hydroxyvitamin D and risk of myocardial infarction in men: a prospective study," Archives of Internal Medicine, vol. 168, no. 11, pp. 1174-1180, 2008.

[59] J. Marniemi, E. Alanen, O. Impivaara et al., "Dietary and serum vitamins and minerals as predictors of myocardial infarction and stroke in elderly subjects," Nutrition, Metabolism and Cardiovascular Diseases, vol. 15, no. 3, pp. 188-197, 2005.

[60] W. B. Grant, H. S. Cross, C. F. Garland et al., "Estimated benefit of increased vitamin $\mathrm{D}$ status in reducing the economic burden of disease in western Europe," Progress in Biophysics and Molecular Biology, vol. 99, no. 2-3, pp. 104-113, 2009.

[61] M. Pfeifer, B. Begerow, H. W. Minne, D. Nachtigall, and C. Hansen, "Effects of a short-term vitamin $\mathrm{D}_{3}$ and calcium 
supplementation on blood pressure and parathyroid hormone levels in elderly women," Journal of Clinical Endocrinology and Metabolism, vol. 86, no. 4, pp. 1633-1637, 2001.

[62] D. P. Trivedi, R. Doll, and K. T. Khaw, "Effect of four monthly oral vitamin D3 (cholecalciferol) supplementation on fractures and mortality in men and women living in the community: randomised double blind controlled trial," The British Medical Journal, vol. 326, no. 7387, pp. 469-472, 2003.

[63] A. Z. LaCroix, J. Kotchen, G. Anderson et al., "Calcium plus vitamin $\mathrm{D}$ supplementation and mortality in postmenopausal women: the women's health initiative calcium-vitamin D randomized controlled trial," Journals of Gerontology A: Biological Sciences and Medical Sciences, vol. 64, no. 5, pp. 559-567, 2009.

[64] E. Theodoratou, I. Tzoulaki, L. Zgaga, and J. P. A. Ioannidis, "Vitamin D and multiple health outcomes: umbrella review of systematic reviews and meta-analyses of observational studies and randomised trials," The British Medical Journal, vol. 348, Article ID g2035, 2014.

[65] M. J. Bolland, A. Grey, G. D. Gamble, and I. R. Reid, “The effect of vitamin D supplementation on skeletal, vascular, or cancer outcomes: a trial sequential meta-analysis," The Lancet Diabetes \& Endocrinology, vol. 2, no. 4, pp. 307-320, 2014.

[66] M. J. Bolland, A. Grey, G. D. Gamble, and I. R. Reid, "Vitamin D supplementation and falls: a trial sequential meta-analysis," The Lancet Diabetes \& Endocrinology, vol. 2, no. 7, pp. 573-580, 2014.

[67] C. F. Garland, E. D. Gorham, S. B. Mohr, and F. C. Garland, "Vitamin D for cancer prevention: global perspective," Annals of Epidemiology, vol. 19, no. 7, pp. 468-483, 2009.

[68] M. Chung, J. Lee, T. Terasawa, J. Lau, and T. A. Trikalinos, "Vitamin D with or without calcium supplementation for prevention of cancer and fractures: an updated meta-analysis for the U.S. Preventive Services Task Force," Annals of Internal Medicine, vol. 155, no. 12, pp. 827-838, 2011.

[69] K. D. Cashman, "A review of vitamin D status and CVD," Proceedings of the Nutrition Society, vol. 73, no. 1, pp. 65-72, 2014.

[70] M. B. Elamin, N. O. Abu Elnour, K. B. Elamin et al., "Vitamin $\mathrm{D}$ and cardiovascular outcomes: a systematic review and metaanalysis," Journal of Clinical Endocrinology and Metabolism, vol. 96, no. 7, pp. 1931-1942, 2011.

[71] S. Muldowney and M. Kiely, "Vitamin D and cardiometabolic health: a review of the evidence," Nutrition Research Reviews, vol. 24, no. 1, pp. 1-20, 2011.

[72] J. A. Ford, G. S. MacLennan, A. Avenell, M. Bolland, A. Grey, and M. Witham, "Cardiovascular disease and vitamin D supplementation: trial analysis, systematic review, and metaanalysis," The American Journal of Clinical Nutrition, vol. 100, no. 3, pp. 746-755, 2014.

[73] V. Kunadian, G. A. Ford, B. Bawamia, W. Qiu, and J. E. Manson, "Vitamin D deficiency and coronary artery disease: a review of the evidence," The American Heart Journal, vol. 167, no. 3, pp. 283-291, 2014.

[74] P. Messa, M. Curreri, A. Regalia, and C. M. Alfieri, "Vitamin $\mathrm{D}$ and the cardiovascular system: an overview of the recent literature," The American Journal of Cardiovascular Drugs, vol. 14, no. 1, pp. 1-14, 2014.

[75] G. Muscogiuri, J. Mitri, C. Mathieu et al., "Mechanisms in endocrinology: vitamin $\mathrm{D}$ as a potential contributor in endocrine health and disease," European Journal of Endocrinology, vol. 171, no. 3, pp. R101-R110, 2014.
[76] R. Chowdhury, S. Kunutsor, A. Vitezova et al., "Vitamin D and risk of cause specific death: systematic review and meta-analysis of observational cohort and randomised intervention studies," The British Medical Journal, vol. 348, Article ID g1903, 2014.

[77] P. Pludowski, M. F. Holick, S. Pilz et al., "Vitamin D effects on musculoskeletal health, immunity, autoimmunity, cardiovascular disease, cancer, fertility, pregnancy, dementia and mortality-a review of recent evidence," Autoimmunity Reviews, vol. 12, no. 10, pp. 976-989, 2013.

[78] N. C. Harvey and C. Cooper, "Vitamin D: some perspective please," The British Medical Journal, vol. 345, no. 7869, Article ID e4695, 2012.

[79] T. Richart, Y. Li, and J. A. Staessen, "Renal versus extrarenal activation of vitamin $\mathrm{D}$ in relation to atherosclerosis, arterial stiffening, and hypertension," The American Journal of Hypertension, vol. 20, no. 9, pp. 1007-1015, 2007.

[80] K. P. Schlingmann, M. Kaufmann, S. Weber et al., "Mutations in CYP24A1 and idiopathic infantile hypercalcemia," The New England Journal of Medicine, vol. 365, no. 5, pp. 410-421, 2011.

[81] K. M. Sanders, A. L. Stuart, E. J. Williamson et al., "Annual highdose oral vitamin D and falls and fractures in older women: a randomized controlled trial," The Journal of the American Medical Association, vol. 303, no. 18, pp. 1815-1822, 2010.

[82] K. M. Sanders, G. C. Nicholson, and P. R. Ebeling, "Is high dose vitamin D harmful?" Calcified Tissue International, vol. 92, no. 2, pp. 191-206, 2013.

[83] P. Welsh and N. Sattar, "Vitamin D and chronic disease prevention," The British Medical Journal, vol. 348, Article ID g2280, 2014.

[84] S. Yusuf, G. Dagenais, J. Pogue, J. Bosch, and P. Sleight, "Vitamin E supplementation and cardiovascular events in highrisk patients. The Heart Outcomes Prevention Evaluation Study Investigators," The New England Journal of Medicine, vol. 342, no. 3, pp. 154-160, 2000.

[85] B. K. Dunn, E. S. Richmond, L. M. Minasian, A. M. Ryan, and L. G. Ford, "A nutrient approach to prostate cancer prevention: the selenium and vitamin E cancer prevention trial (SELECT)," Nutrition and Cancer, vol. 62, no. 7, pp. 896-918, 2010.

[86] J. E. Rossouw, G. L. Anderson, R. L. Prentice et al., "Risks and benefits of estrogen plus progestin in healthy postmenopausal women: principal results from the women's health initiative randomized controlled trial," The Journal of the American Medical Association, vol. 288, no. 3, pp. 321-333, 2002.

[87] K. Muse, "After the Women's Health initiative-what to tell our patients," Southern Medical Journal, vol. 95, no. 9, pp. 957-959, 2002.

[88] O. S. Miettinen, "The clinical trial as a paradigm for epidemiologic research," Journal of Clinical Epidemiology, vol. 42, no. 6, pp. 491-498, 1989.

[89] K. J. Rothman, S. Greenland, and T. L. Lash, Modern Epidemiology, Lippincott Williams \& Wilkins, Philadelphia, Pa, USA, 2008.

[90] P. Lips, T. Duong, A. Oleksik et al., "A global study of vitamin D status and parathyroid function in postmenopausal women with osteoporosis: baseline data from the multiple outcomes of raloxifene evaluation clinical trial," Journal of Clinical Endocrinology and Metabolism, vol. 86, no. 3, pp. 12121221, 2001.

[91] E. Hyppönen and C. Power, "Hypovitaminosis D in British adults at age $45 \mathrm{y}$ : nationwide cohort study of dietary and lifestyle predictors," The American Journal of Clinical Nutrition, vol. 85, no. 3, pp. 860-868, 2007. 
[92] T. Hagenau, R. Vest, T. N. Gissel et al., "Global vitamin D levels in relation to age, gender, skin pigmentation and latitude: an ecologic meta-regression analysis," Osteoporosis International, vol. 20, no. 1, pp. 133-140, 2009.

[93] P. Lips, "Vitamin D status and nutrition in Europe and Asia," Journal of Steroid Biochemistry and Molecular Biology, vol. 103, no. 3-5, pp. 620-625, 2007.

[94] I. S. Fetahu, J. Hobaus, and E. Kallay, "Vitamin D and the epigenome," Frontiers in Physiology, vol. 5, article 164, 2014.

[95] K. M. Flegal, B. I. Graubard, D. F. Williamson, and R. S. Cooper, "Reverse causation and illness-related weight loss in observational studies of body weight and mortality," The American Journal of Epidemiology, vol. 173, no. 1, pp. 1-9, 2011.

[96] P. Autier, M. Boniol, C. Pizot, and P. Mullie, "Vitamin D status and ill health: a systematic review," The Lancet Diabetes \& Endocrinology, vol. 2, no. 1, pp. 76-89, 2014.

[97] R. Gama, J. L. Waldron, H. L. Ashby et al., "Hypovitaminosis $\mathrm{D}$ and disease: consequence rather than cause?" The British Medical Journal, vol. 345, no. 7872, Article ID e5706, 2012.

[98] M. Bochud, "On the use of Mendelian randomization to infer causality in observational epidemiology," European Heart Journal, vol. 29, no. 20, pp. 2456-2457, 2008.

[99] M. Bochud and V. Rousson, "Usefulness of Mendelian randomization in observational epidemiology," International Journal of Environmental Research and Public Health, vol. 7, no. 3, pp. 711728,2010 .

[100] S. K. Kunutsor, S. Burgess, P. B. Munroe, and H. Khan, "Vitamin D and high blood pressure: causal association or epiphenomenon?" European Journal of Epidemiology, vol. 29, no. 1, pp. 1-14, 2014.

[101] K. S. Vimaleswaran, A. Cavadino, D. J. Berry et al., "Association of vitamin D status with arterial blood pressure and hypertension risk: a Mendelian randomisation study," The Lancet Diabetes \& Endocrinology, vol. 2, no. 9, pp. 719-729, 2014.

[102] Z. Ye, S. J. Sharp, S. Burgess et al., "Association between circulating 25-hydroxyvitamin D and incident type 2 diabetes: a mendelian randomisation study," The Lancet Diabetes \& Endocrinology, vol. 3, no. 1, pp. 35-42, 2015.

[103] A. M. Rose, "Vitamin D testing: clinical and laboratory considerations," Medical Laboratory Observer, vol. 45, no. 5, pp. 8-14, 2013.

[104] A. Prentice, G. R. Goldberg, and I. Schoenmakers, "Vitamin D across the lifecycle: physiology and biomarkers," The American Journal of Clinical Nutrition, vol. 88, no. 2, pp. 500S-506S, 2008.

[105] I. Tzoulaki, K. C. Siontis, E. Evangelou, and J. P. A. Ioannidis, "Bias in associations of emerging biomarkers with cardiovascular disease," JAMA Internal Medicine, vol. 173, no. 8, pp. 664-671, 2013.

[106] C. J. L. Farrell, S. Martin, B. McWhinney, I. Straub, P. Williams, and M. Herrmann, "State-of-the-art vitamin D assays: a comparison of automated immunoassays with liquid chromatography-tandem mass spectrometry methods," Clinical Chemistry, vol. 58, no. 3, pp. 531-542, 2012.

[107] B. W. Hollis, "Assessment of circulating 25(OH)D and $1,25(\mathrm{OH})_{2} \mathrm{D}$ : emergence as clinically important diagnostic tools," Nutrition Reviews, vol. 65, no. 8, part 2, pp. S87-S90, 2007.

[108] S. J. Bruce, B. Rochat, A. Béguin et al., "Analysis and quantification of vitamin D metabolites in serum by ultra-performance liquid chromatography coupled to tandem mass spectrometry and high-resolution mass spectrometry-a method comparison and validation," Rapid Communications in Mass Spectrometry, vol. 27, no. 1, pp. 200-206, 2013.

[109] E. Giovannucci, "Strengths and limitations of current epidemiologic studies: vitamin D as a modifier of colon and prostate cancer risk," Nutrition Reviews, vol. 65, no. 8, part 2, pp. S77S79, 2007.

[110] F. R. Greer, "25-Hydroxyvitamin D: functional outcomes in infants and young children," The American Journal of Clinical Nutrition, vol. 88, no. 2, pp. 529S-533S, 2008.

[111] C. J. E. Lamberg-Allardt and H. T. Viljakainen, "25Hydroxyvitamin D and functional outcomes in adolescents," The American Journal of Clinical Nutrition, vol. 88, no. 2, pp. 534S-536S, 2008.

[112] B. Dawson-Hughes, "Serum 25-hydroxyvitamin D and functional outcomes in the elderly," The American Journal of Clinical Nutrition, vol. 88, no. 2, pp. 537S-540S, 2008.

[113] J. E. Manson, S. S. Bassuk, I.-M. Lee et al., “The VITamin D and OmegA-3 TriaL (VITAL): rationale and design of a large randomized controlled trial of vitamin D and marine omega3 fatty acid supplements for the primary prevention of cancer and cardiovascular disease," Contemporary Clinical Trials, vol. 33, no. 1, pp. 159-171, 2012.

[114] S. Pilz, K. Kienreich, A. Tomaschitz et al., "Vitamin D and cardiovascular disease: update and outlook," Scandinavian Journal of Clinical and Laboratory Investigation Supplements, vol. 243, pp. 83-91, 2012.

[115] S. Pilz, F. Rutters, and J. M. Dekker, "Disease prevention: vitamin D trials," Science, vol. 338, no. 6109, p. 883, 2012.

[116] K. Michaëlsson, "The puzzling world of vitamin D insufficiency," The Lancet Diabetes \& Endocrinology, vol. 2, no. 4, pp. 269-270, 2014.

[117] "Vitamin D: chasing a myth?" The Lancet Diabetes \& Endocrinology, vol. 2, no. 1, p. 1, 2014.

[118] V. Prasad, A. Cifu, and J. P. A. Ioannidis, "Reversals of established medical practices: evidence to abandon ship," The Journal of the American Medical Association, vol. 307, no. 1, pp. 37-38, 2012.

[119] I. Guessous and M. Bochud, "Reply to the letter to the editor 'Vitamin D deficiency and cardiovascular disease' by Ahmed et al," Swiss Medical Weekly, vol. 143, Article ID w13822, 2013.

[120] J. P. A. Ioannidis, "Biomarker failures," Clinical Chemistry, vol. 59, no. 1, pp. 202-204, 2013.

[121] K. Kupferschmidt, "Uncertain verdict as vitamin D goes on trial," Science, vol. 337, no. 6101, pp. 1476-1478, 2012.

[122] N. Sattar, P. Welsh, M. Panarelli, and N. G. Forouhi, "Increasing requests for vitamin $\mathrm{D}$ measurement: costly, confusing, and without credibility," The Lancet, vol. 379, no. 9811, pp. 95-96, 2012.

[123] R. H. Fletcher, "Review: vitamin $\mathrm{D}_{3}$ supplementation may reduce mortality in adults; vitamin $\mathrm{D}_{2}$ does not," Annals of Internal Medicine, vol. 161, no. 2, article JC5, 2014.

[124] I. R. Reid, M. J. Bolland, and A. Grey, "Effects of vitamin D supplements on bone mineral density: a systematic review and meta-analysis," The Lancet, vol. 383, no. 9912, pp. 146-155, 2014. 


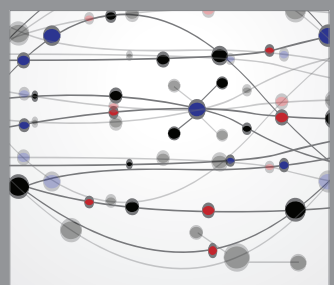

The Scientific World Journal
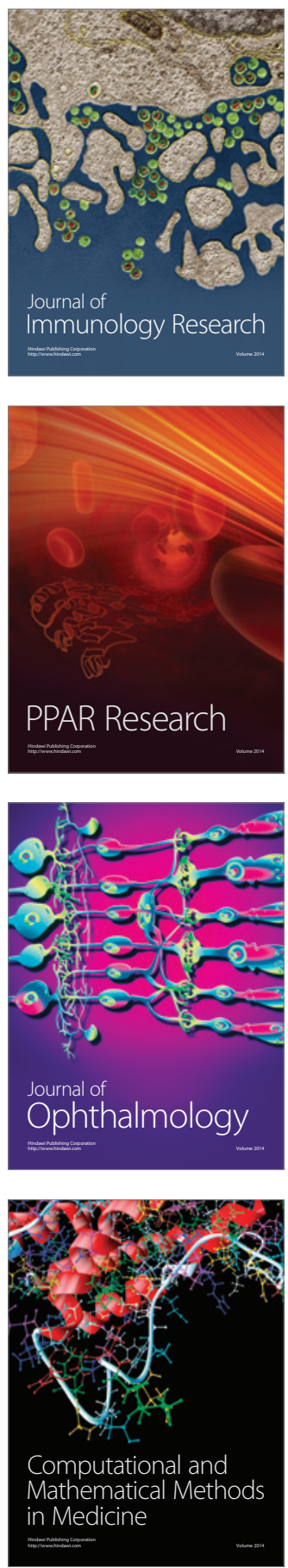

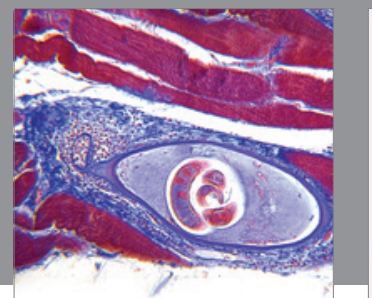

Gastroenterology

Research and Practice
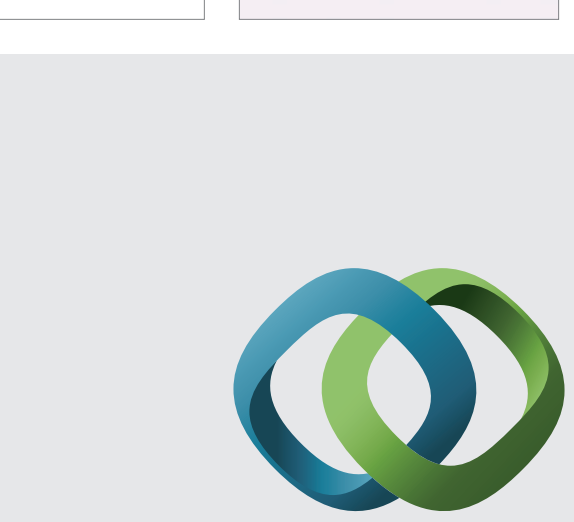

\section{Hindawi}

Submit your manuscripts at

http://www.hindawi.com
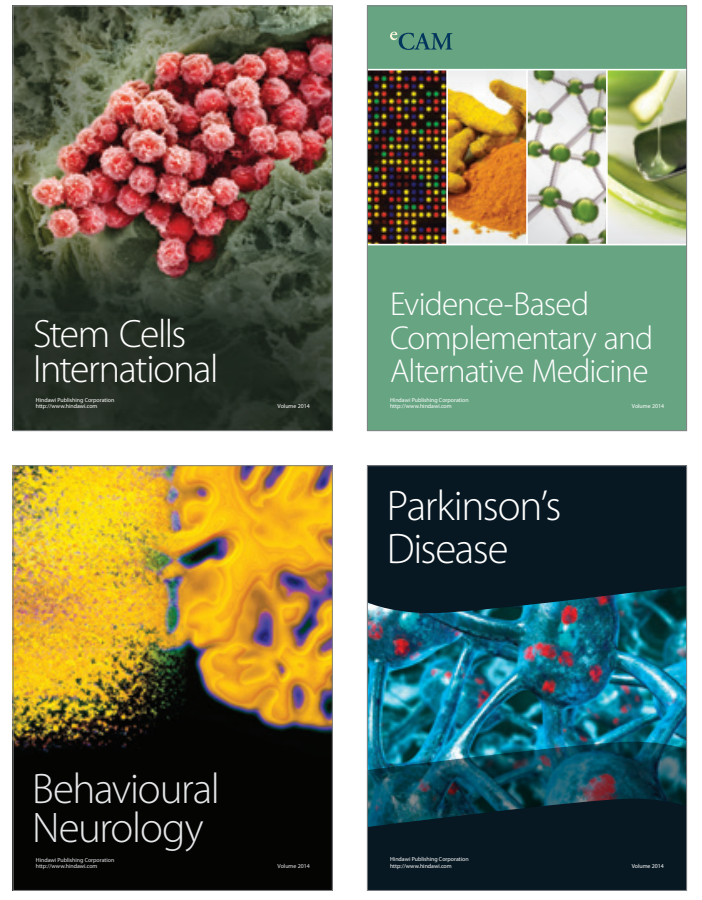
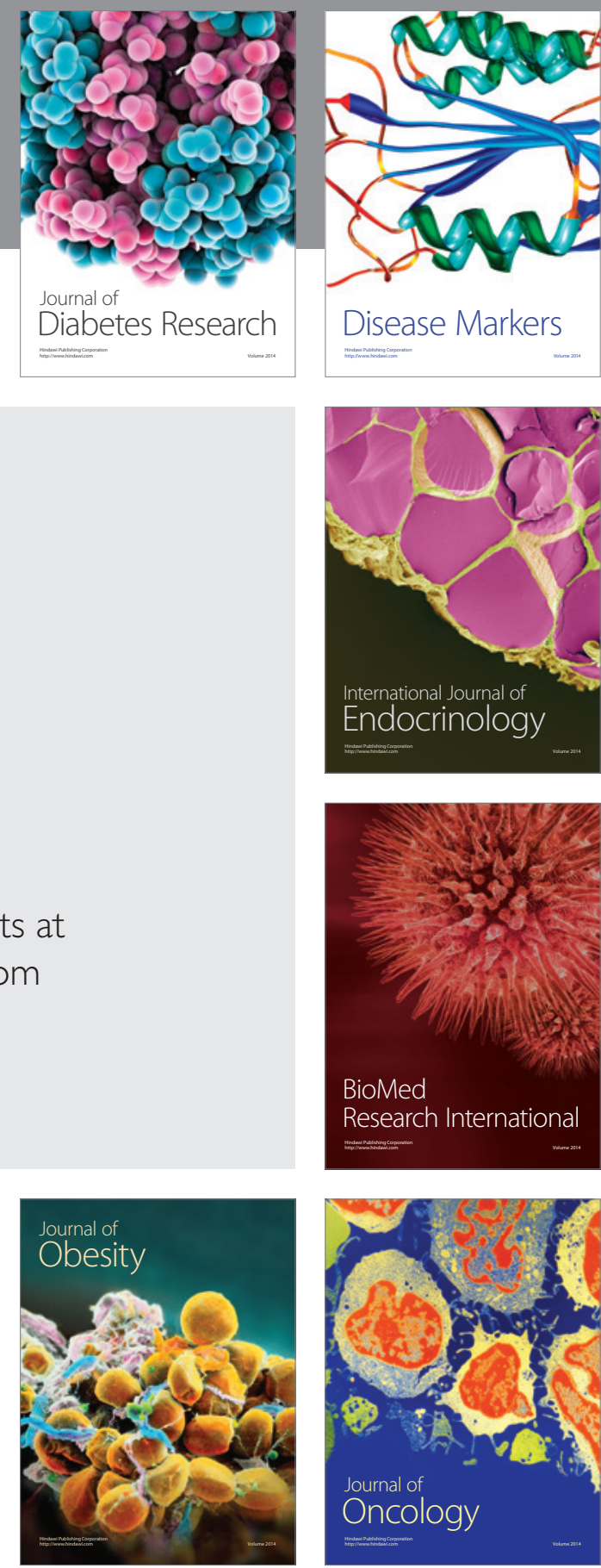

Disease Markers
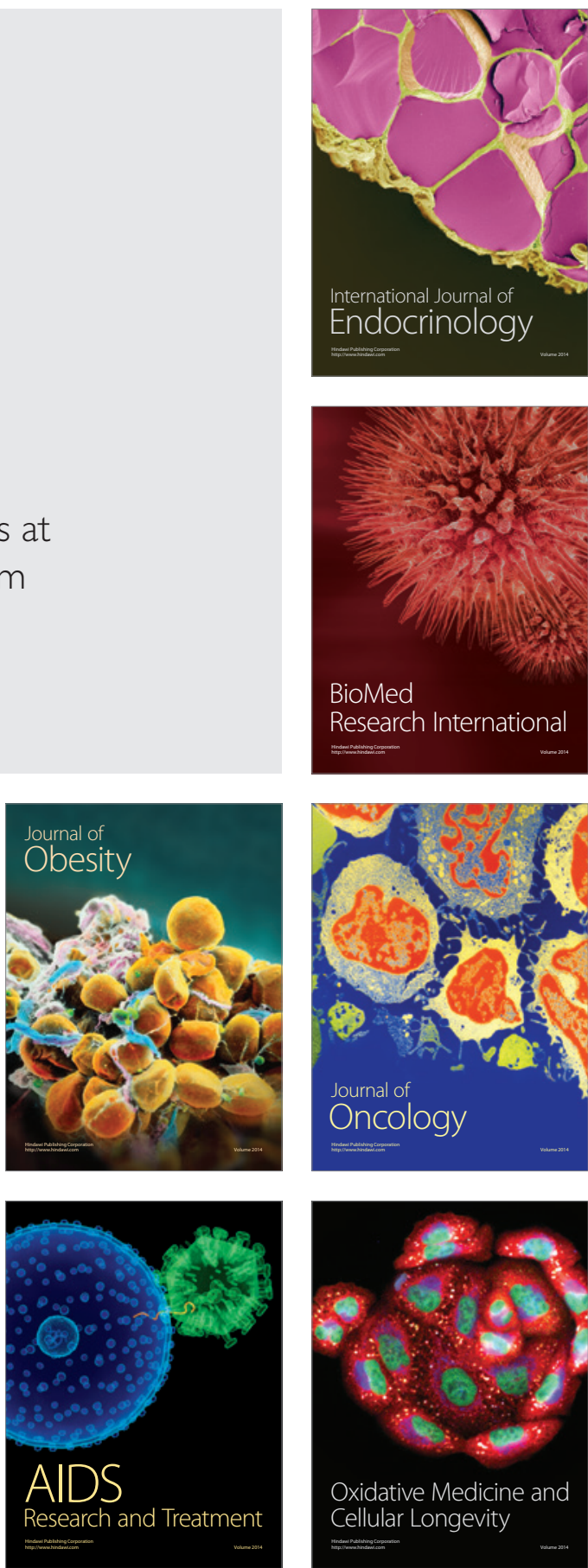